\title{
Safety and Performance of Sirolimus-Eluting Coronary Stent System with Biodegradable Polymer: A Retrospective Analysis in Real-World Patient Population
}

\author{
Vithala Surya Prakasa Rao*, A. S. V. Narayana Rao, Pannala Lakshmi Narasimha Kapardhi, \\ Priyen Kantilal Shah, Revanur Viswanath, Satyajit Govindrao Mehetre, \\ Avanindra Kumar Srivastava
}

Department of Cardiology, Apollo Hospitals, Hyderabad, India

Email: *vithalarao5@gmail.com, *sp.vithala@yahoo.com

How to cite this paper: Prakasa Rao, V.S., Narayana Rao, A.S.V., Kapardhi, P.L.N., Shah, P.K., Viswanath, R., Mehetre, S.G. and Srivastava, A.K. (2017) Safety and Performance of Sirolimus-Eluting Coronary Stent System with Biodegradable Polymer: A Retrospective Analysis in Real-World Patient Population. World Journal of Cardiovascular Diseases, 7, 163-173.

https://doi.org/10.4236/wjcd.2017.75015

Received: May 2, 2017

Accepted: May 24, 2017

Published: May 27, 2017

Copyright $\odot 2017$ by authors and Scientific Research Publishing Inc. This work is licensed under the Creative Commons Attribution International License (CC BY 4.0).

http://creativecommons.org/licenses/by/4.0/

(c) (i) Open Access

\begin{abstract}
Background and Aim: Newer generation coronary stent systems with low profile metallic frame, biodegradable polymer coating and potent but safe anti-restenosis drug from "limus family" are emerging as safe and effective stents. To evaluate the safety and performance of Metafor SES (Meril life Sciences Pvt. Ltd., Vapi, India) in consecutive patients in a real-world population. Methods: The study was a retrospective, non-randomized, single-center study which evaluated the data of 127 patients who underwent percutaneous coronary intervention (PCI) treated with Metafor SES from February 2012 to February 2015 and mean follow-up period of those patients was $3.6 \pm 0.6$ years. The primary endpoint was a major adverse cardiac event (MACE) including cardiac death, myocardial infarction (MI), and target lesion revascularization (TLR). In addition, Stent thrombosis (ST) was analyzed at respective follow-up period. Results: A total of 127 patients (mean age: $53.70 \pm 8.41$ years and 99 males) were included. Among those 80 (63\%) patients had hypertension and 58 (45.7\%) patients with diabetes mellitus.At follow-up, MACE in form of TLR was observed in $2(1.6 \%)$ patients only. No cardiac death or stent thrombosis was reported in any patient. A total of 169 lesions were treated with the Metafor SES (1.3 stents per lesion). The $38.4 \%$ of patients treated with the Metafor SES with lesion length $\geq 24 \mathrm{~mm}$, and the procedural success was $100 \%$. Conclusions: The lower incidence of MACE in uncontrolled and real world population at long term follow-up clearly depicts the prolonged safety and performance of the Metafor SES.
\end{abstract}

\section{Keywords}

Biodegradable Polymer, Cobalt-Chromium, Metafor SES, 
Sirolimus-Eluting Stent, Stent Thrombosis

\section{Introduction}

Cardiovascular disease (CVD) is one of the leading causes of mortality in India [1]. According to the World Health demography 2008 report, global deaths from CVD will extend from 17.1 million in 2004 to 23.4 million in 2030, thus, predetermined CVD is the leading cause of morbidity and mortality worldwide [2].

Drug eluting stent (DES) has established for the treatment for coronary artery disease $(C A D)$ over the past decade by effectively reducing in-stent restenosis and for the target vessel revascularization (TVR) [3] [4] [5]. Despite that, some adverse events of durable polymers which were used in first-generation DES such as inflammation, vascular hypersensitivity reaction, neo-atherosclerosis, late and very late stent thrombosis (ST) were observed in extensive research [6] [7] [8]. Consequently, several clinical studies have conducted and addressed the above mentioned adverse events through alteration of the stent platforms with blood and tissue compatibility, outer layer of the stent surface, effective antirestenosis drug, and polymer carriers [5] [9] [10]. Likewise, there remains concern about the inflammatory responses even though some non-biodegradable polymer-coated drug eluting stent pronounced to be safe for long term [11]. Thus, biodegradable polymers are being considered and analysed to acquire and carry drugs. Polymers like poly (lactic acid) (PLA), poly (glycolic acid) and their copolymer, poly (lactic-co-glycolic acid) (PLGA), are most prevalent as they sight characteristics to get completely degraded and metabolized in the body [12] [13]. Moreover, biodegradable polymer would have improved safety and performance of DES as they deliver controlled release of anti-restenotic agent and gradual degradation of coating [14] [15]. Hence, efforts to modify or use different coating materials on the stent surface is one of the efficient ways to alter characteristics of the stent surface and enhance the stent's biocompatibility, and consequently reduce the episode of thrombosis and restenosis.

Thus, DES such as Metafor ${ }^{\mathrm{TM}}$ (CE approved) sirolimus-eluting coronary stent (SES) system (Meril Life Sciences Pvt. Ltd., Vapi, India) has been developed with an objective to reduce the adverse effects of existing DES. In a real-world patient population biodegradable polymer have demonstrated excellent safety and performance in CAD patients as quoted in several studies of DES [16] [17]. The Metafor SES (Meril Life Sciences Pvt. Ltd., Vapi, India) uses L605 cobalt chromium alloy as its stent platform which is coated with a biodegradable and biocompatible polymer to deliver sirolimus. The primary aim of this retrospective study was to evaluate clinical performance of the Metafor SES sirolimus-eluting coronary stent in the treatment of patients enrolled in every day practice at the Apollo Hospitals, Hyderabad, Telangana, India. The primary endpoint was a major adverse cardiac event (MACE) including cardiac death, myocardial infarction (MI), and target lesion revascularisation (TLR). In addition, Stent throm- 
bosis (ST) was analyzed at respective follow-up period.

\subsection{Study Design and Patient Population}

This was a retrospective, non-randomized, single-center study with the main purpose of evaluating the safety and efficacy of the Metafor sirolimus-eluting stent (SES) implantation for consecutive unselected patients treated in daily practice including those with high-risk characteristics and complex lesions. A total of 127 consecutive patients who underwent PCIs with the use of Metafor SES (Meril Life Sciences Pvt. Ltd., Vapi, India) between February 2012 and February 2015 at the Apollo Hospitals, Hyderabad, India were included in this study.

The inclusion criteria were aged $\geq 18$ years, signs and symptoms of ischemic heart disease and those patients who had at least one Metafor SES implanted. However, patients who refused to provide informed consent were excluded from the study. The study was conducted in accordance with the Helsinki declaration and informed consent was obtained from all patients. This study was approved by Independent Ethics Committee.

\subsection{Description of the Study Stent}

The Metafor SES is a stainless-steel alloy; CE approved NexGen ${ }^{\mathrm{Tw}}$, coronary stent. The Metafor SES has an ultrathin cobalt-chromium platform as its stent platform with a unique cell design comprising of an intelligent mix of open and close cells, which has a strut thickness of $65 \mu \mathrm{m}$ with biodegradable and biocompatible polymer base and a drug load of $1.25 \mu \mathrm{g}$ sirolimus $/ \mathrm{mm}^{2}$.

In Metafor SES, poly-L-lactic (PLL) and poly (lactic-co-glycolic acid) (PLGA) polymers are used to achieve a controlled drug release from drug eluting stent. Metafor SES uses a validated formulation of low dose sirolimus $\left(1.25 \mu \mathrm{g} / \mathrm{mm}^{2}\right)$ timed to elute in 30 - 40 days from a biodegradable polymer base which degrades simultaneously. The Metafor SES is available in sizes ranging from 8 to $48 \mathrm{~mm}$ length and from 2.00 to $4.50 \mathrm{~mm}$ diameter.

\subsection{Interventional Procedure and Adjunctive Medications}

All patients received a loading dose of $325 \mathrm{mg}$ of aspirin and $300 \mathrm{mg}$ clopidogrel or $60 \mathrm{mg}$ of prasugrel or $90 \mathrm{mg}$ of ticagrelor. The procedure was performed according to the standard treatment guidelines of each participating center.

All the patients received dual antiplatelet therapy (DAPT) (aspirin 75 - 300 $\mathrm{mg}$ /day indefinitely and clopidogrel $75 \mathrm{mg}$ /day or prasugrel $10 \mathrm{mg}$ /day or ticagrelor $90 \mathrm{mg}$ twice daily for at least 12 months) after the procedure.

\subsection{Definitions and Endpoints}

The primary endpoint of the study was to determine the rate of MACE; which is defined as the aggregate of cardiac death, MI, and TLR procedure during the follow-up period after the index procedure. Deaths were classified as cardiac or noncardiac. Deaths from uncertain causes were reported as cardiac. The ST was 
also evaluated in this study which was classified according to the definitions of the Academic Research Consortium [18]. Procedural success was defined as successful stent placement at the desired position with $<30 \%$ residual stenosis. At follow-up, data were collected relating to current clinical status, any hospitalization after PCI and occurrence of any MACE and ST.

\subsection{Statistical Analysis}

Categorical data were presented as counts and percentages. Continuous variables were recorded as mean \pm standard deviation. The time-to-event curve was presented as per the Kaplan-Meier method. All data were processed using the Statistical Package for Social Sciences, version 15 (SPSS, Chicago, IL, USA). Fisher's exact testwas used for comparison of MACE events.

\section{Results}

\subsection{Patient Characteristics}

The baseline demographics of the patients are edged in Table 1 . The analysis

Table 1. Baseline characteristics of the study population.

\begin{tabular}{|c|c|}
\hline Variables & Patients $(n=127)$ \\
\hline \multicolumn{2}{|l|}{ Patient Demographics } \\
\hline Age (Years) & $53.70 \pm 8.41$ \\
\hline Male & $99(78 \%)$ \\
\hline BMI $\left(\mathrm{kg} / \mathrm{m}^{2}\right)$, Mean $\pm \mathrm{SD}$ & $24.54 \pm 3.92$ \\
\hline \multicolumn{2}{|l|}{ Baseline Medical History } \\
\hline Smokers, n (\%) & $12(9.4 \%)$ \\
\hline Diabetes mellitus, n (\%) & $58(45.7 \%)$ \\
\hline Hypertension, n (\%) & $80(63 \%)$ \\
\hline \multicolumn{2}{|l|}{ Cardiac History } \\
\hline Angina, $\mathrm{n}(\%)$ & $4(3.1 \%)$ \\
\hline Previous myocardial infarction, $\mathrm{n}(\%)$ & $9(7.1 \%)$ \\
\hline Prior PCI, n (\%) & $22(17.3 \%)$ \\
\hline Prior CABG, n (\%) & $4(3.1 \%)$ \\
\hline Previous CAD, n (\%) & $25(19.7 \%)$ \\
\hline \multicolumn{2}{|l|}{ Cardiac Status, n (\%) } \\
\hline Stable angina & $85(66.9 \%)$ \\
\hline Unstable angina & $38(29.9 \%)$ \\
\hline Recent MI & $70(55.1 \%)$ \\
\hline $\mathrm{CAD}$ & $118(92.9 \%)$ \\
\hline Thrombolysis & $10(7.9 \%)$ \\
\hline Acute coronary Syndrome & $10(7.9 \%)$ \\
\hline
\end{tabular}

${ }^{\star}$ CABG-coronary artery bypass grafting; CAD-coronary artery disease; PCI-percutaneous coronary intervention. ${ }^{\dagger}$ Data are presented as mean $\pm \mathrm{SD}$ or as number and percentage. 
consists of baseline clinical data and follow-up data collected at $3.6 \pm 0.6$ years mean follow-up period. Apollo hospitals, Hyderabad, India was a site where total of 127 consecutive patients were enrolled and data were collected for analysis. Out of 127 patients, 99 (78\%) were males, $58(45.7 \%)$ of patients had diabetes, and $80(63 \%)$ of patients were hypertensive. Among 127 patients, 85 (66.9\%) and $38(29.9 \%)$ patients were treated with a diagnosis of stable angina and unstable angina. The mean age was $53.70 \pm 8.41$ years. In total $9.4 \%$ were current smokers whereas, 118 (92.95) patients were having CAD. In addition, history of previous $\mathrm{MI}, \mathrm{CAD}$, and prior revascularization procedures occurred in patients with $7.1 \%, 19.7 \%$, and $17.3 \%$ respectively.

\subsection{Procedural Characteristics}

Metafor SES have treated total of 169 lesions (1.3 stents per lesion). The greater number of patients (38.4\%) treated withMetafor SES with lesion length $\geq 24 \mathrm{~mm}$. In defiance of this, our procedural success was $100 \%$. Single-vessel disease was more frequent $(71.7 \%)$ in this study revealed in coronary angiography. Also, baseline analysis showed mean percent diameter stenosis of $84.2 \% \pm 10.70 \%$ that was treated with Metafor SES stent. The most frequent target vessel was left anterior descending (LAD) artery (37.9\%). Specifications of the lesion and procedural characteristics are outlined in Table 2.

\subsection{Clinical Outcomes}

At the mean follow-up period of $3.6 \pm 0.6$ years, the primary endpoint occurred

Table 2. Lesion and procedural characteristics.

\begin{tabular}{|c|c|}
\hline Variables & Patients $(\mathrm{n}=127)$ \\
\hline \multicolumn{2}{|l|}{ Lesion characteristics } \\
\hline Single vessel disease & $91(71.7 \%)$ \\
\hline Double vessel disease & $30(23.6 \%)$ \\
\hline Triple vessel disease & $6(4.7 \%)$ \\
\hline \multicolumn{2}{|l|}{ Target vessel locations } \\
\hline Left anterior descending artery, $\mathrm{n}(\%)$ & $64(37.9 \%)$ \\
\hline Left circumflex artery, n (\%) & $31(18.34 \%)$ \\
\hline Right coronary artery, n (\%) & $42(24.85 \%)$ \\
\hline Others, n (\%) & $32(18.93 \%)$ \\
\hline \multicolumn{2}{|l|}{ Procedure characteristics } \\
\hline Total number of lesions, $\mathrm{n}$ & 183 \\
\hline Total number of lesions treated with study stent, $\mathrm{n}$ & 169 \\
\hline Lesion per patient & 1.33 \\
\hline$\%$ Occlusion, Mean \pm SD & $84.2 \pm 10.70$ \\
\hline Number of occlusions (100\% stenosis) (\%) & $17.52 \%$ \\
\hline Average stent length, Mean \pm SD & $21.53 \pm 7.78$ \\
\hline Average stent diameter, Mean \pm SD & $2.90 \pm 0.34$ \\
\hline
\end{tabular}


in $2(1.6 \%)$ of 127 patients, consisting of $0(0.0 \%)$ cardiac deaths, $0(0.0 \%) \mathrm{MI}$, and $2(1.6 \%)$ TLR. No stent thrombosis was reported. As there were only 2 $(1.6 \%)$ cases of in-stent restenosis, those went on to require TLR of the right coronary artery, one via PCI and the other via intentional subintimal stenting. The summary of MACE during mean follow-up period of $3.6 \pm 0.6$ years is outlined in Table 3. Cumulative probability of survival was found to be $98.4 \%$ in time-toevent analysis performed by Kaplan-Meier method (Figure 1).

Table 3. Cumulative clinical events for mean follow-up of $3.6 \pm 0.6$ years for patients receiving Metafor SES.

\begin{tabular}{cc}
\hline Events & Mean Follow-up \\
\hline MACE, n (\%) & $2(1.6 \%)$ \\
Cardiac death, n (\%) & $0(0 \%)$ \\
Myocardial infarction, n (\%) & $0(0 \%)$ \\
TLR, n (\%) & $2(1.6 \%)$ \\
TVR, n (\%) & $0(0 \%)$ \\
Stent thrombosis, n (\%) & $0(0 \%)$
\end{tabular}

${ }^{*}$ MACE: Major adverse cardiac events (Cardiac death, Myocardial infarction and TLR); TLR: Target lesion revascularization.

Kaplan Meier curve for Mace free incidence

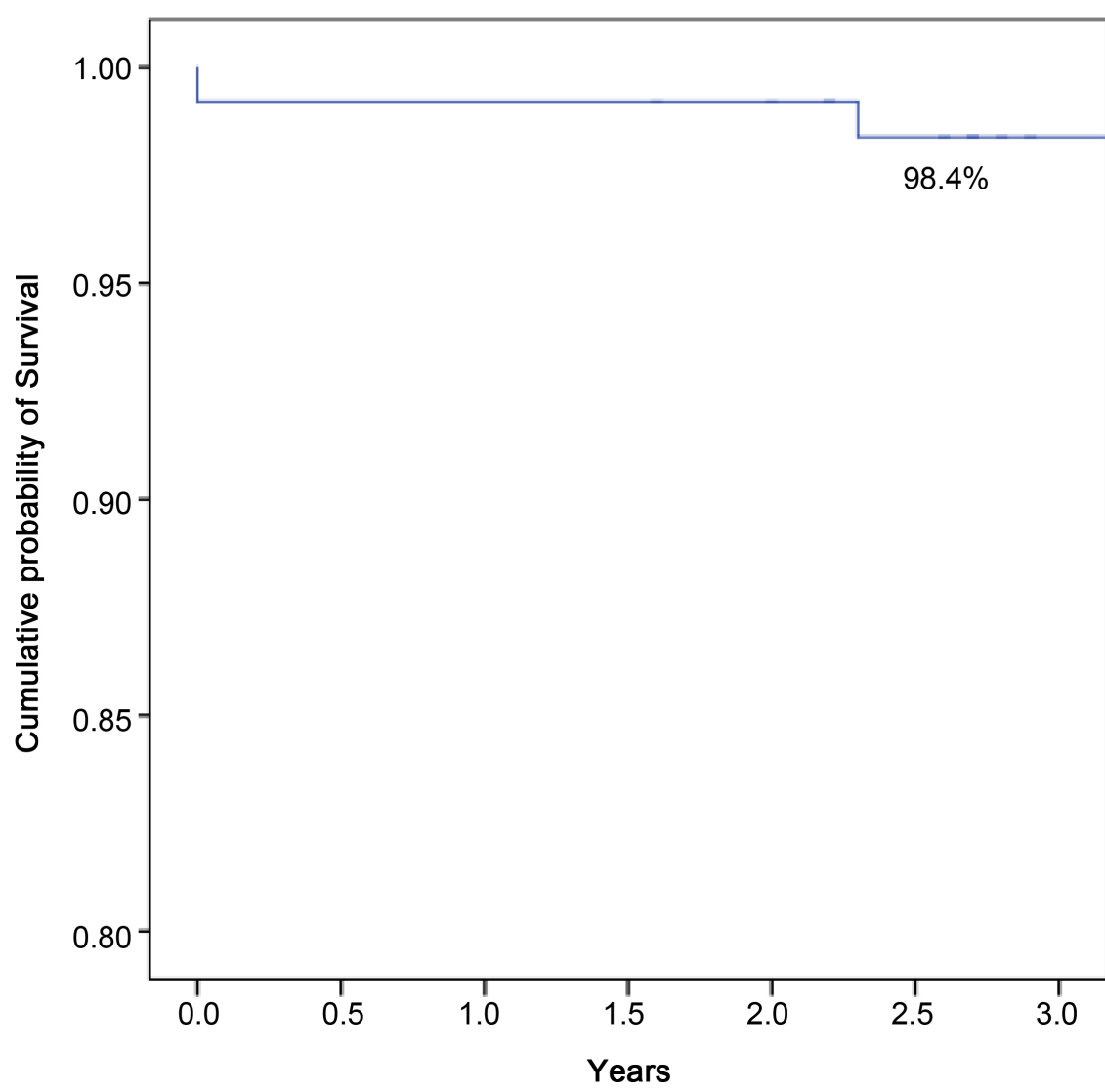

Figure 1. The time-to-event curve at mean follow-up of $3.6 \pm 0.6$ years by Kaplan Meier method. 


\section{Discussion}

Metafor SES treated a total of 127 patients included in this retrospective study. Construction of Metafor SES consist an ultrathin cobalt-chromium platform and utilizes a hybrid cell design which allows for morphology mediated expansion from the middle to the edges. Asset of such structure is that it allows quick arterial reviving and encouraging procedural outcomes. Results of the current study stated that, in CAD patients during mean follow-up period of $3.6 \pm 0.6$ years, the Metafor SES exhibited favourable safety and performance in a "realworld" consecutive patient.

Demographic data showed $63 \%$ of the patients had hypertension, $45.7 \%$ had diabetes, and $66.9 \%$ had stable angina plays significant role in real clinical practice and allowing us to evaluate the Metafor SES in a "real-world" patient population. Comprehensive studies report that the presence of a durable polymer with lack of biocompatibility in first-generation DES was associated with inflammation and vascular hypersensitivity reaction delay in re-endothelization, and most importantly, with late and very late stent thrombosis and death [6] [19]. Thus, biodegradable polymers are being considered and investigated in lots of clinical studies to deliver drugs.

Several clinical studies were conducted and compared to analyze the safety and performance of biodegradable polymers. The NEXT trial reported that one-year clinical outcome after implantation of both biolimus-eluting stent and everolimus-eluting stent was phenomenal, with a low rate of TLR and stent thrombosis [20]. Along with NEXT trial, the NOBORI 2 study also concluded good and sustained performance of biodegradable polymers in high-risk patients with indicative comorbidities and/or complex lesions [21]. Moreover, the safety and performance of biodegradable polymers with limus family of DES were firmly accepted in a real-world patient population [17] [20]. In this study, we collected and analyzed the data of Metafor SES with the perspective to evaluate the safety and performance of Metafor SES.

The biodegradable polymer is used in the Metafor SES which reduces the limitations of durable polymers. It was observed that there are lot of factors like stent design, strut thickness, type of antiproliferative agent, drug elution kinetics, elution time, and type of polymer which affect the safety and performance of coronary stent platforms [22]. Likewise, strut thickness is a very influential parameter which matters local inflammation at the lesion site. Two studies confirmed that the rate of restenosis was decreased according to strut thickness. First, in the ISAR-STEREO study, the rate of restenosis was reduced from $25.8 \%$ to $15.0 \%$ (strut thickness $140 \mu \mathrm{m}$ Vs. $50 \mu \mathrm{m}$ ). Second, in the ISAR-STEREO-2 trial, two platforms were examined that had identical designs but altered only in strut thickness [23] [24]. The Metafor SES is comprised of thin struts which elevate the device flexibility and device performance. Moreover, The Metafor SES based on a hybrid cell design, which eliminates the classic dog-boning effect and thus, lead to excellent stent positioning, even in complex lesions.

It was observed that there are some restrictions of first-in-man trials which 
cannot be assumed to "real-world" patients with greater risk or with complex coronary anatomy. A well defined post-market surveillance study can provide significant clinical data of real-world patients treated in a routine clinical practice. Hence, Metafor SES in consecutive patients for the treatment of CAD is carried out as retrospective observational study to evaluate clinical outcomes.

The most convincing clinical results of this retrospective study are $100 \%$ procedural success rate; low rates of MACE (1.6\%) with no deaths and ST at follow-up. Moreover, MACE occurred in $1.6 \%$ of patients consisting of 2 cases of TLR only, which is statistically significant than the $12.9 \%$ that was observed in the Endeavor stent $(\mathrm{p}<0.001)$ when compared and the $11.0 \%$ that was noted in NOBORI stent $(\mathrm{p}<0.001)$ [25] [26]. Additionally, the SPIRIT II trial observed MACE rates $(7.2 \%)$ in 223 patients, which also demonstrate significant difference in MACE $(1.6 \%)$ observed in Metafor SES ( $p$ 0.001) [10].

Moreover, the major improvements in clinical results were type of polymer and stent platform. When BioMatrix Flex biolimus-eluting stent is compared the strut thickness $112 \mu \mathrm{m}$ is much higher than $65 \mu \mathrm{m}$ strut thickness. In this study, the MI (0\%) and TLR (1.6\%) significantly differ than MI with 7.0\% ( $\mathrm{p}<0.001)$ and TLR with 7.8\% $(\mathrm{p}<0.01)$ of the BioMatrix stent [27] [28]. Hence, the Metafor SES with biodegradable polymer and thinner struts has potential to improve clinical outcomes.

In current study, $45.7 \%$ of patients were diabetic and $63 \%$ of patients were hypertensive. Even with the complexity of disorders in the present study population, lesser MACE rate (1.6\%) at mean follow-up of $3.6 \pm 0.6$ years demonstrated favourable clinical outcomes of the Metafor SES. Therefore, this observation specifies the excellent performance of the Metaphor SES in a real-world patient population.

\section{Study Limitations}

There are some limitations of this study, they are: 1) Retrospective and observational design; 2) This was a non-randomised, single-arm study without comparison groups. Therefore, long-term ( $>5$ years) follow-up is essential to assess the factual event rates.

\section{Conclusion}

In conclusion, the lower episodes of MACE in uncontrolled and real world patient population at long term follow-up clearly represent the prolonged safety and performance of the Metafor SES. Therefore, Metafor stent could be an acceptable substitute even in high risk patients to contemporary DES which are presently available in the market.

\section{Acknowledgements}

Authors would like to thank all the patients who were participated in this retrospective study. 


\section{Disclosures}

The authors declare no conflict of interest.

\section{References}

[1] Prabhakaran, D., Jeemon, P. and Roy, A. (2016) Cardiovascular Diseases in India: Current Epidemiology and Future Directions. Circulation, 133, 1605-1620. https://doi.org/10.1161/CIRCULATIONAHA.114.008729

[2] Ashavaid, T.F., Ponde, C.K., Shah, S. and Jawanjal, M. (2012) Cardiovascular Disease in India. Clinics in Laboratory Medicine, 32, 217-230. https://doi.org/10.1016/j.cll.2012.04.001

[3] Simard, T., Hibbert, B., Chong, A.Y., et al. (2012) Unprotected Left Main Coronary Artery Stenting with Zotarolimus (Endeavor) Drug-Eluting Stents: A Single Center Retrospective Experience. Catheterization and Cardiovascular Interventions, 80, E15-E22. https://doi.org/10.1002/ccd.23244

[4] Milewski, K., Gasior, P., Samborski, S., et al. (2016) Evaluation of Safety and Efficacy of NexGen-An Ultrathin Strut and Hybrid Cell Design Cobalt-Chromium Bare Metal Stent Implanted in a Real Life Patient Population-The Polish NexGen Registry. Postępy w Kardiologii Interwencyjnej, 12, 217-223.

https://doi.org/10.5114/aic.2016.61642

[5] Ma, X., Wu, T. and Robich, M.P. (2012) Drug-Eluting Stent Coatings. Interventional Cardiology, 4, 73-83.

[6] Souza, C.F., El Mouallem, A.M., de Brito Junior, F.S., et al. (2013) Safety and Efficacy of Biolimus-Eluting Stent with Biodegradable Polymer: Insights from EINSTEIN (Evaluation of Next-Generation Drug-Eluting STEnt IN Patients with Coronary Artery Disease) Registry. Einstein (Sao Paulo), 11, 350-356. https://doi.org/10.1590/S1679-45082013000300015

[7] Serruys, P.W. and Daemen, J. (2007) Late Stent Thrombosis: A Nuisance in Both Bare Metal and Drug-Eluting Stents. Circulation, 115, 1433-1439; Discussion 1439. https://doi.org/10.1161/CIRCULATIONAHA.106.666826

[8] Park, S.J., Kang, S.J., Virmani, R., Nakano, M. and Ueda, Y. (2012) In-Stent Neoatherosclerosis: A Final Common Pathway of Late Stent Failure. Journal of the American College of Cardiology, 59, 2051-2057. https://doi.org/10.1016/j.jacc.2011.10.909

[9] Hamon, M., Niculescu, R., Deleanu, D., et al. (2013) Clinical and Angiographic Experience with a Third-Generation Drug-Eluting Orsiro Stent in the Treatment of Single de Novo Coronary Artery Lesions (BIOFLOW-I): A Prospective, First-inMan Study. EuroIntervention, 8, 1006-1011. https://doi.org/10.4244/EIJV8I9A155

[10] Garg, S., Serruys, P., Onuma, Y., et al. (2009) 3-Year Clinical Follow-Up of the XIENCE V Everolimus-Eluting Coronary Stent System in the Treatment of Patients with de Novo Coronary Artery Lesions:. JACC: Cardiovascular Interventions, 2, 1190-1198. https://doi.org/10.1016/j.jcin.2009.10.002

[11] Finn, A.V., Nakazawa, G., Joner, M., et al. (2007) Vascular Responses to Drug Eluting Stents: Importance of Delayed Healing. Arteriosclerosis, Thrombosis, and Vascular Biology, 27, 1500-1510. https://doi.org/10.1161/ATVBAHA.107.144220

[12] Hollinger, J.O. (1983) Preliminary Report on the Osteogenic Potential of a Biodegradable Copolymer of Polyactide (PLA) and Polyglycolide (PGA). Journal of Biomedical Materials Research, 17, 71-82. https://doi.org/10.1002/jbm.820170107

[13] BaoLin, G. and Ma, P.X. (2014) Synthetic Biodegradable Functional Polymers for Tissue Engineering: A Brief Review. Science China Chemistry, 57, 490-500. 
https://doi.org/10.1007/s11426-014-5086-y

[14] Parsa, E., Saroukhani, S., Majlessi, F., et al. (2016) Biodegradable-Polymer Biolimus-Eluting Stents versus Durable-Polymer Everolimus-Eluting Stents at One-Year Follow-Up: A Registry-Based Cohort Study. Texas Heart Institute Journal, 43, 126 130. https://doi.org/10.14503/THIJ-14-4997

[15] Goyal, B.K., Kalmath, B.C., Kawar, R., et al. (2013) Experience with BioMatrix BES and Other DES in All-Comers Setting: A Retrospective Overview. Indian Heart Journal, 65, 678-682. https://doi.org/10.1016/j.ihj.2013.10.014

[16] Belardi, J.A., Widimsky, P., Neumann, F.J., Mauri, L. and Albertal, M. (2013) Real-World Safety and Effectiveness Outcomes of a Zotarolimus-Eluting Stent: Final 3-Year Report of the RESOLUTE International Study. Journal of Interventional Cardiology, 26, 515-523. https://doi.org/10.1111/joic.12051

[17] Mehta, A.B., Chandra, P., Dalal, J., et al. (2013) One-Year Clinical Outcomes of BioMatrix $^{\mathrm{Tm}}$-Biolimus A9 ${ }^{\mathrm{Tm}}$ Eluting Stent: The e-BioMatrix Multicenter Post Marketing Surveillance Registry in India. Indian Heart Journal, 65, 593-599. https://doi.org/10.1016/j.ihj.2013.08.031

[18] Cutlip, D.E., Windecker, S., Mehran, R., et al. (2007) Clinical End Points in Coronary Stent Trials a Case for Standardized Definitions. Circulation, 115, 2344-2351. https://doi.org/10.1161/CIRCULATIONAHA.106.685313

[19] Stefanini, G.G., Byrne, R.A., Serruys, P.W., et al. (2012) Biodegradable Polymer drug-Eluting Stents Reduce the Risk of Stent Thrombosis at 4 Years in Patients Undergoing Percutaneous Coronary Intervention: A Pooled Analysis of Individual Patient Data from the ISAR-TEST 3, ISAR-TEST 4, and LEADERS Randomized Trials. European Heart Journal, 33, 1214-1222. https://doi.org/10.1093/eurheartj/ehs086

[20] Natsuaki, M., Kozuma, K., Morimoto, T., et al. (2013) Biodegradable Polymer Biolimus-Eluting Stent versus Durable Polymer Everolimus-Eluting Stent: A Randomized, Controlled, Noninferiority Trial. Journal of the American College of Cardiology, 62, 181-190. https://doi.org/10.1016/j.jacc.2013.04.045

[21] Danzi, G.B., Chevalier, B., Urban, P., et al. (2012) Clinical Performance of a Drug-Eluting Stent with a Biodegradable Polymer in an Unselected Patient Population: The NOBORI 2 Study. EuroIntervention, 8, 109-116. https://doi.org/10.4244/EIJV8I1A17

[22] Navarese, E.P., Tandjung, K., Claessen, B., et al. (2013) Safety and Efficacy Outcomes of First and Second Generation Durable Polymer Drug Eluting Stents and Biodegradable Polymer Biolimus Eluting Stents in Clinical Practice: Comprehensive Network Meta-Analysis. BMJ, 347, f6530. https://doi.org/10.1136/bmj.f6530

[23] Kastrati, A., Mehilli, J., Dirschinger, J., et al. (2001) Intracoronary Stenting and Angiographic Results: Strut Thickness Effect on Restenosis Outcome (ISAR-STEREO) trial. Circulation, 103, 2816-2821. https://doi.org/10.1161/01.CIR.103.23.2816

[24] Pache, J., Kastrati, A., Mehilli, J., et al. (2003) Intracoronary Stenting and Angiographic Results: Strut Thickness Effect on Restenosis Outcome (ISAR-STEREO-2) Trial. Journal of the American College of Cardiology, 41, 1283-1288.

[25] Maeng, M., Tilsted, H.H., Jensen, L.O., et al. (2012) 3-Year Clinical Outcomes in the Randomized SORT OUT III Superiority Trial Comparing Zotarolimus- and Sirolimus-Eluting Coronary Stents. JACC: Cardiovascular Interventions, 5, 812-818. https://doi.org/10.1016/j.jcin.2012.04.008

[26] Natsuaki, M., Kozuma, K., Morimoto, T., et al. (2015) Final 3-Year Outcome of a Randomized Trial Comparing Second-Generation Drug-Eluting Stents Using Either Biodegradable Polymer or Durable Polymer: NOBORI Biolimus-Eluting versus 
XIENCE/PROMUS Everolimus-Eluting Stent Trial. Circulation: Cardiovascular Interventions, 8, e002817.

https://doi.org/10.1161/CIRCINTERVENTIONS.115.002817

[27] Wykrzykowska, J., Serruys, P., Buszman, P., et al. (2011) The Three Year Follow-Up of the Randomised "All-Comers" Trial of a Biodegradable Polymer Biolimus-Eluting Stent versus Permanent Polymer Sirolimus-Eluting Stent (LEADERS). EuroIntervention, 7, 789-795. https://doi.org/10.4244/EIJV7I7A125

[28] Capodanno, D., Dipasqua, F. and Tamburino, C. (2011) Novel Drug-Eluting Stents in the Treatment of de Novo Coronary Lesions. Vascular Health and Risk Management, 7, 103-118. https://doi.org/10.2147/VHRM.S11444

Submit or recommend next manuscript to SCIRP and we will provide best service for you:

Accepting pre-submission inquiries through Email, Facebook, LinkedIn, Twitter, etc. A wide selection of journals (inclusive of 9 subjects, more than 200 journals)

Providing 24-hour high-quality service

User-friendly online submission system

Fair and swift peer-review system

Efficient typesetting and proofreading procedure

Display of the result of downloads and visits, as well as the number of cited articles Maximum dissemination of your research work

Submit your manuscript at: http://papersubmission.scirp.org/

Or contact wjcd@scirp.org 